\title{
Mapeamento de fluxo de valor aplicado à reestruturação organizacional
}

Victor Carneiro Bonadio vbonadio@aluno.ufabc.edu.br Universidade Federal do ABC (UFABC), Santo André, São Paulo, Brasil.

Delmo Alves de Moura delmo.moura@ufabc.edu.b Universidade Federal do ABC (UFABC), Santo André, São Paulo, Brasil.

\begin{abstract}
RESUMO
Esse artigo é resultado de um estudo de caso realizado em uma empresa brasileira prestadora de serviços de transportes. Essa empresa que já foi líder de mercado, frente a crises econômicas e a entrada de novos concorrentes perdeu a liderança do segmento. Nesse contexto, vários departamentos da empresa passaram por restruturações organizacionais em busca da redução de custos, afetando diretamente o departamento de vendas focada no business-to-business (B2B), que estava organizada de forma descentralizada e passou a ter uma organização centralizada. 0 desenvolvimento das novas práticas de mercado está diretamente relacionado com o modo que as organizações se relacionam com seus clientes, contudo desenvolver e sustentar uma relação de fidelidade com o cliente no B2B ainda é pouco explorado. Para esse estudo será utilizada a metodologia de mapa de fluxo de valor a fim de entender quais desperdícios existiam na antiga estrutura organizacional (descentralizada) que poderiam ter sido otimizados dentro da nova estrutura (centralizada). Dessa forma esse artigo tem por objetivo entender a viabilidade da utilização da metodologia e identificar quais processos de vendas geram valor ao cliente dentro do B2B. Os resultados demonstraram que a utilização da metodologia de mapa de fluxo de valor aplicado a serviços, mais especificamente ao departamento de vendas é de fato eficaz para a identificação dos principais desperdícios. A utilização da ferramenta pela empresa, previamente a alteração organizacional poderia ter levado a uma estrutura ainda mais preparada para atender ao cliente, pois em ambos os mapas foram encontradas as mesmas oportunidades de melhoria.
\end{abstract}

PALAVRAS-CHAVE: Mapa de fluxo de valor. Estruturas organizacionais. B2B. 


\section{INTRODUÇÃO}

A economia globalizada e os novos avanços tecnológicos modificaram a dinâmica de mercado exigindo que os provedores de produtos ou serviços busquem melhorar sua eficácia nas operações e seu posicionamento estratégico. Nesse contexto o mercado vem se adaptando, deixando de ser centrado no produto ou serviço para ser centrado no relacionamento com o cliente, para isso as expectativas dos clientes devem ser supridas de maneira mais abrangente e de forma mais eficiente. Sendo assim as empresas buscam adaptar-se a as novas dinâmicas de mercado e ganhar vantagens competitivas sobre seus concorrentes (BOSE, 2002).

De acordo com Rich (2000), um dos pontos mais significativos no desenvolvimento das novas práticas de mercado está diretamente relacionado com o modo que as organizações se relacionam com seus clientes. Xu e Walton (2005) explicam que a aquisição de conhecimento sobre o cliente é uma ferramenta estratégica para ganhar vantagens competitivas no mercado moderno. Essa evolução do mercado requer que as companhias empreguem novas formas de conhecer seus clientes para então identificar suas reais necessidades e prover a eles as soluções exatas sem que isso impacte diretamente nos custos da companhia.

Apesar dessa nova tendência, Woo e Ennew (2004) expõem que dentro do mercado business-to-business (B2B) a qualidade no relacionamento com os clientes permanece pouco explorada pelas empresas. Para Caceres e Paparoidamis (2007), desenvolver e sustentar uma relação de fidelidade com o cliente no B2B ainda é um ponto difícil de alcançar. Com o objetivo de se preencher essa lacuna, este artigo busca entender como as empresas que adotam o modelo B2B devem se organizar para melhor atender seus clientes e quais atividades de agregam valor na relação entre empresa e cliente?

A fim de responder essa questão, foi selecionada uma empresa brasileira prestadora de serviços de transportes, que passou por uma reestruturação organizacional de seu time de vendas indiretas com foco no B2B, como objeto de um estudo de caso. Pode-se assim inferir que este estudo de caso será único, pois segundo Stake (2007) ocorre quando não existem muitas situações semelhantes para que sejam feitos estudos comparativos. Propõe-se então a utilização da metodologia de mapa de fluxo de valor para compreender quais atividade da organização agregam valor nas relações com o cliente e quais delas poderiam ser revisadas e ajustadas.

\section{ESTRUTURA ORGANIZACIONAL}

Segundo Kovoor-Misra (2009), crises, mudanças organizacionais como reorganizações, fusões e aquisições se tornaram parte integral do ambiente de trabalho. Essas situações podem mudar a percepção das principais características de uma organização, ou até mesmo como os funcionários se identificam com a organização. Nesse contexto mudanças organizacionais podem ser percebidas como ameaças ou oportunidades e essa percepção pode variar de acordo com a fase da reorganização e com os atores envolvidos. Para os gestores esses períodos podem ser utilizados como aprendizado para corrigir falhas ou 
estruturas organizacionais deficientes que por muitas vezes foram o que levaram a própria crise (KOVOOR-MISRA, 2009).

Em muitas organizações a força de vendas é considerada uma das áreas de maior relevância para a companhia, pois é essa a área que estabelece relações diretas com cliente, que por fim está diretamente relacionado com a performance da organização como um todo. Apesar da relevância companhias líderes de vendas concordam que existe oportunidade no aumento do faturamento maximizando a eficiência de sua própria força de vendas (ZOLTNERS, SINHA, LORIMER, 2008).

Como a organização da força vendas é afetada não só por forças e decisões que se originam dentro da empresa, mas como por forças que se originam externamente, Zoltners, Sinha e Lorimer (2008) propõe um processo de decisão para lidar com os diferentes componentes e complexidades do Mundo de Vendas (Figura 1) com o objetivo de se alcançar uma maior eficiência da força de vendas, em quatro (4) etapas:

a) Identificar como eventos afetam a estratégia de vendas e marketing;

b) Determinar qual organização da força de vendas é necessária;

c) Especificar quais habilidades e capacidades são necessárias a força de vendas;

d) Encorajar a força de vendas a executar as novas atividades com eficiência.

Figura 1- Componentes do Mundo de Vendas

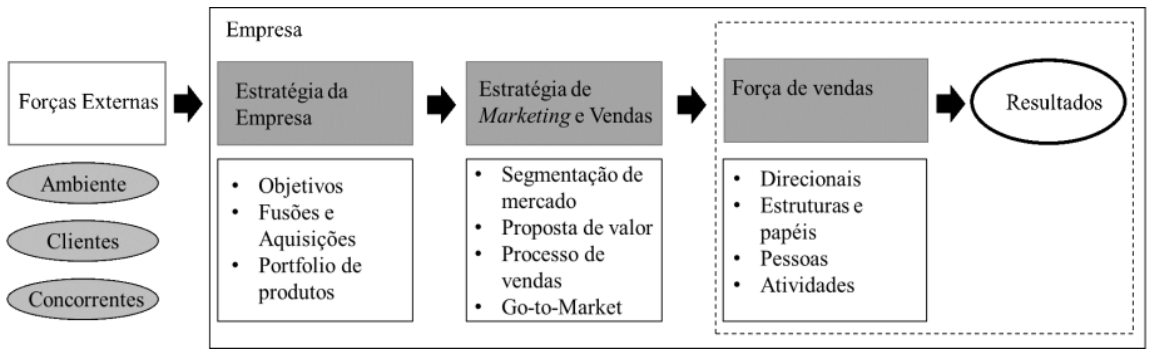

Fonte: Adaptado de Zoltners, Sinha e Lorimer (2008).

\section{METODOLOGIA}

O mapa o de fluxo de valor (VSM) será adotado para entender potenciais desperdícios na área de vendas da companhia objeto do estudo, buscando compreender os fluxos de valor e identificar desperdícios por meio do desenho do mapa do fluxo de valor presente e futuro. Como nesse estudo de caso a empresa passou por uma recente reestruturação organizacional, o objetivo será desenhar o mapa presente, com base na antiga estrutura, e o mapa futuro com base na estrutura atual (SINGH, GARG, SHARMA, 2010; BRAGLIA, FROSOLINI, ZAMMORI, 2009; EMILIANI, STEC, 2004; LASA et al., 2008).

Para Rother e Shook (1999) e Tapping and Shuker (2003) a análise do fluxo de valor e desperdício do VSM deve-se ser utilizado um procedimento de 4 (quatro) etapas:

a) Seleção de uma família de produtos; 
b) Desenho do mapa presente. Que consiste em listar os processos que devem representar atividade que adicionam ou não valor ao estado atual;

c) Desenho do mapa futuro. Um procedimento sistemático para a melhoria das diretrizes do estado futuro baseados na teoria VSM de Rother e Shook (1999);

d) Atingimento do estado futuro. Um plano de mapa de valor e diretrizes de gerenciamento são desenhadas para se atingir o estado futuro.

Emiliani e Stec (2004) defendem que o mapeamento do fluxo de valor pode ser usado para mapear qualquer tipo de processo de negócios, incluindo: vendas business-to-business, vendas no varejo, comércio eletrônico, saúde, educação e serviços governamentais. Visando sempre em eliminar os desperdícios e agregar valor a atividades que os consumidores desejam e estão dispostos a pagar.

Para Bonaccorsi, Carmignani e Zammori, (2011) o VSM também pode ser utilizada para o mapeamento de serviços, no qual a primeira etapa consisti em escolher o fluxo de valor a ser melhorado. A identificação do fluxo de valor deverá ser feita considerando aqueles serviços que apresentam a maior recorrência de pedidos ou a maior receita para a empresa, de forma a identificar quais são e onde estão as maiores incidências de desperdício. Essa identificação deverá ser promovida por meio de coleta de dados proveniente dos clientes e ao final desse processo os dados coletados deverão: esclarecer as necessidades dos clientes, verificar a categoria correção do defeito dando peso de importância a cada um e por fim estabelecer qual destes é mais crítico para a empresa (BONACCORSI, CARMIGNANI, ZAMMORI, 2011).

A partir da identificação do fluxo principal a ser mapeada serão desenhados 2 (dois) mapas de valor, considerando para isso os dados obtidos na experiência da empresa na adoção de um novo modelo organizacional. Os mapas de valor serão desenhados conforme apresentados por Barber e Tietje (2013), na parte inferior do mapa serão descritas as subatividades dos vendedores bem como o tempo despendido em cada uma delas, enquanto na parte de superior do mapa estarão descritas as subatividades e o tempo dispendido dos clientes.

As subatividades estarão descritas em retângulos e serão agrupadas de acordo com cada etapa do processo de venda, de acordo Bonaccorsi, Carmignani e Zammori (2011) e Braglia, (2006) serão classificadas como agregam valor, necessárias ou não agregam valor (desperdícios). Os retângulos brancos indicarão as aditividades que agregam valor, os retângulos pretos irão indicar as aditividades que não agregam valor, porém necessárias, e os sombreados em cinza as atividades que de fato não agregam valor, conforme a Figura 2. 
Figura 2 - Modelo de mapa de fluxo de valor

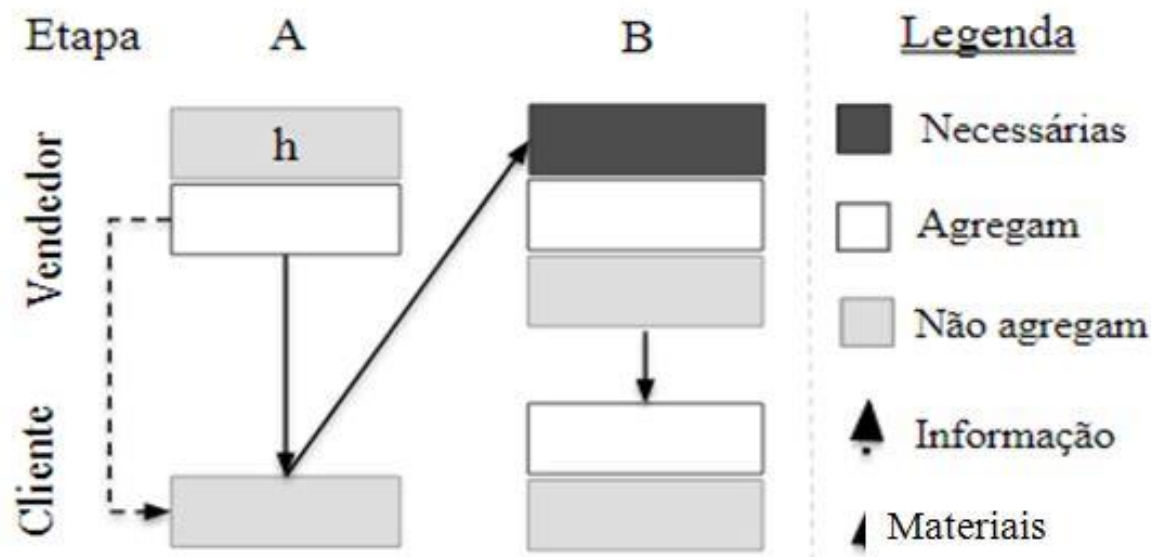

Fonte: Adaptado de Bonaccorsi, Carmignani e Zammori (2011) e Braglia, (2006).

Por fim, setas sólidas representam toda e qualquer troca de informação entre cliente e vendedor que podem ocorrer por telefone, comutador ou pessoalmente. Já as setas tracejadas indicam as trocas de documentos e materiais (BARBER, TIETJE, 2013).

\section{COLETA DE DADOS}

Esse estudo foi conduzido em uma empresa brasileira prestadora de serviços de transportes. Os dados foram coletados através de entrevistas com os principais clientes da empresa e com os vendedores que faziam parte da companhia, e estavam no departamento de vendas antes e depois das alterações organizacionais. Partindo da metodologia de mapa de fluxo de valor, os clientes foram entrevistados para se definir qual fluxo de valor seria objeto de análise e só então os vendedores foram entrevistados para se compreender quais atividades de fato agregavam valor ao cliente e quais eram desperdícios.

\section{Entrevistas com a Figura do Cliente}

Segundo Bonaccorsi, Carmignani e Zammori, (2011), o primeiro passo é definir qual fluxo do processo de vendas deverá ser o objeto de análise. Para este artigo serão coletados inputs dos clientes, por meio de uma entrevista em grupo, que segundo May (2004), deve ser composta por " 8 a 12 pessoas que, guiadas por um entrevistador, discutem o(s) tópico(s) em pauta". Nesse estudo de caso foi identificado quais fluxo do departamento de vendas, na visão do cliente agrega maior valor no processo de vendas. Isso posto, o foco será direcionado para o entendimento das atividades que por fim irão resultar em vendas para a empresa e apresentam alguma deficiência. Barber e Tietje (2013) e Keyte e Locher (2004) apresentam as potenciais fontes de desperdício no processo de vendas (Quadro 1). 
Quadro 1 - Fontes potenciais de desperdício no processo de Vendas

\begin{tabular}{|c|r|}
\hline Desperdício & Exemplo \\
\hline Superprodução & Gerar soluções antes que o cliente esteja pronto para comprar \\
\hline Tempo de espera & $\begin{array}{r}\text { Excesso de suprimentos de brochuras impressas } \\
\hline \text { Transporte }\end{array}$ \\
\hline Processamento & $\begin{array}{r}\text { Esperando a aprovação de outros na organização de vendas ou } \\
\text { clientes, e à espera de informações dos clientes }\end{array}$ \\
\hline Inventários & Erros nos dados, design, fatura e proposta \\
\hline Movimentações & $\begin{array}{r}\text { Caminhar de/para copiadora, arquivamento central, fax, outros } \\
\text { escritórios ou ainda voar e dirigir para reuniões e compromissos }\end{array}$ \\
\hline Defeitos & Distribuição de documentos para revisão e aprovação \\
\hline Comportamentos & $\begin{array}{r}\text { Autoridade e responsabilidade limitada, comando e controle de } \\
\text { gestão, inadequados. Ferramentas tecnológicas disponíveis. }\end{array}$ \\
\hline
\end{tabular}

Fonte: Adaptado de Keyte, Locher (2004).

\section{Entrevistas com a Figura do Vendedor}

As atividades foram identificadas e caracterizadas por meio de uma entrevista não estruturada com os vendedores, responsáveis pelo contato com o cliente, que atuaram tanto antes quanto depois da reestruturação do time de vendas, a adoção desse modelo de entrevista se deve ao fato de permitir ao entrevistado responder perguntas dentro da sua própria estrutura de referências, pois são esses agentes que detém o domínio da atividade principal e de suas subatividades (MAY, 2004).

\section{ESTUDO DE CASO}

O estudo de caso foi realizado em uma empresa brasileira prestadora de serviços de transportes que recentemente passou por profundas mudanças organizacionais. Tais alterações impactaram sobretudo o departamento de vendas indiretas com foco no business-to-business que estava organizada de forma descentralizada e passou a ter uma organização centralizada em busca de redução de custos.

O modelo anterior estava estruturado em uma matriz e bases de vendas espalhadas por todo território nacional (Figura 3). A estrutura matricial era responsável pelo desenho de estratégias e acompanhamento do desempenho das vendas, enquanto as bases serviam de ponte entre a companhia, clientes e intermediários, ficando a cargo da manutenção do relacionamento e solução de temas operacionais. 
Figura 3 - Modelo de mapa de fluxo de valor

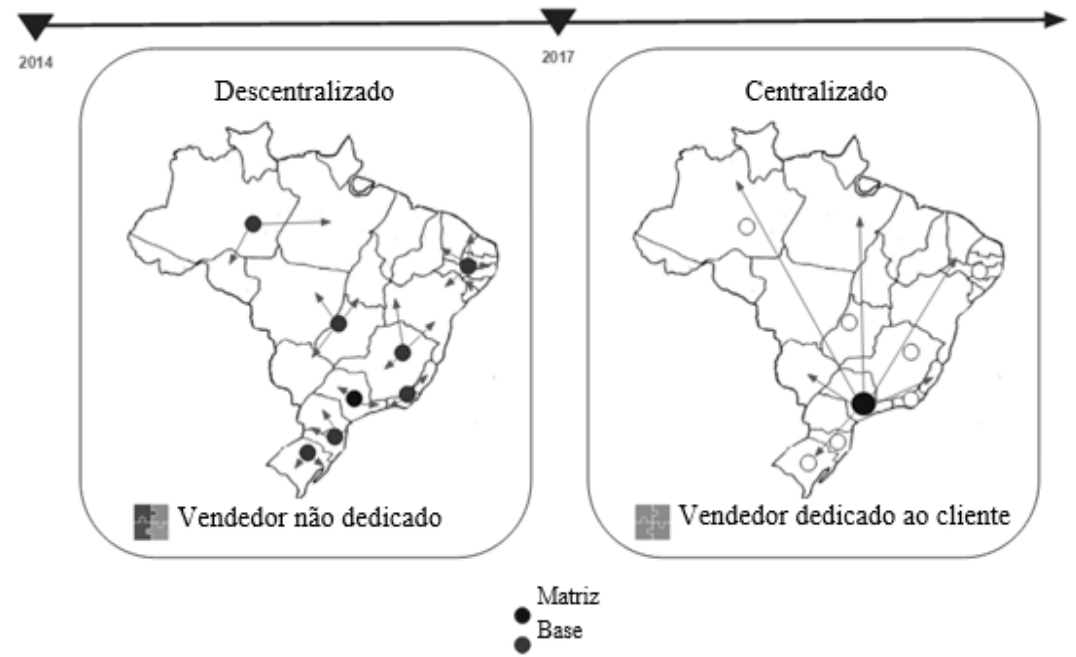

Fonte: Pesquisa de campo (2017)

Cada base contava com sua própria micro estrutura organizacional: gerente, coordenadores e vendedores. Os vendedores eram a ponta dessa cadeia e tinham em sua carteira intermediários e clientes, agregado funções como: visitar clientes, visitar intermediários, executar ações de marketing e solucionar problemas operacionais.

Essa forma de estrutura altamente capilarizada permitia um atendimento mais regionalizado, contudo além de representar um alto custo para a companhia, esse modelo apresentava algumas deficiências, sobretudo no atendimento aos clientes. Os vendedores, que desempenham funções distintas, acabavam por não oferecer um atendimento especializado ao cliente.

Outra deficiência levantada nesse modelo era quanto o distanciamento entre matriz e bases. Essa distância passou a dificultar a comunicação intra organizacional da companhia, que passou a encontrar dificuldades em cascatear as decisões e diretrizes da companhia de forma homogênea. Em meio à crise econômica de 2016 e na busca pela redução de custos, esse modelo que já apresentava sinais de deficiência foi reestruturado.

A organização em bases de vendas foi eliminada e o time de vendas foi realocado apenas na matriz. Os vendedores passaram a ter funções específicas e a organização passou a contar com time especializado para o atendimento aos clientes, no qual os vendedores não mais precisariam atender intermediários ou resolver problemas operacionais.

Esperava-se que com essa nova estrutura a empresa seria mais eficiente e traria melhores resultados, sobretudo das vendas indiretas destinadas ao B2B. Contudo esse novo modelo apresenta alguns riscos, como por exemplo, o distanciamento entre as necessidades do cliente e os serviços oferecidos pela companhia e a dificuldade de gerenciar os clientes espalhados pelo Brasil de uma forma centralizada.

Surge assim a oportunidade para identificar dentro de cada estrutura organizacional apresentada (centralizada e descentralizada) quais fluxos e atividades geram maior valor para o cliente. Dessa forma propõe-se a utilização 
do mapeamento do fluxo de valor, que por fim resultará no desenho de um modelo ideal para o atendimento do cliente.

\section{RESULTADOS}

Conforme apresentado na metodologia o primeiro passo para a aplicação do SVM é a identificação do fluxo a ser analisado, isso posto fora conduzida uma entrevista em grupo com 20 dos principais clientes da empresa. Nessa entrevista foram abordados temas pertinentes ao processo de mudança organizacional que culminou na reestruturação do time de vendas e então foi aberto um espaço para que os clientes fizessem perguntas e tirassem dúvidas sobre a nova estrutura.

O sentimento de "abandono" foi algo transversal e recorrente durante todas as entrevistas, em enumeras ocasiões o tema foi abordado e reiterado por diferentes clientes, "A empresa não está presente" - J. R., "A empresa largou o mercado... ...hoje não defendo mais a empresa" V. L., nesse contexto a nova estrutura do time de vendas centralizada, com uma equipe dedica ao atendimento do cliente, foi muito bem recebida.

Os clientes identificaram na nova estrutura um canal de comunicação e por enumeras vezes solicitaram a manutenção do contato entre as empresas. Dessa forma os desenhos dos mapas de o fluxo de valor serão realizados sob a estrutura de atendimento e comunicação entre a empresa e seus clientes. Sendo que o próximo passo será entender por meio de entrevistas não estruturadas com os vendedores como se dava esse contato anterior e posterior à mudança organizacional e por fim desenhar os mapas de fluxo de valor.

\section{MAPA PASSADO - ATENDIMENTO DESCENTRALIZADO}

Como identificado anteriormente o processo a ser mapeado será quanto ao atendimento do cliente por parte da empresa, Figura 4. Isso posto, foram identificados junto ao vendedor 3 momentos principais nessa relação, a primeira diz respeito a preparação do vendedor para a visita ao cliente $(A)$, a segunda o momento da visita em si (B) e por fim o retorno que o vendedor deve dar ao seu cliente (C). Durante o desenho do mapa de fluxo de valor, dentro da estrutura organizacional descentralizada, a figura o intermediário ganhou força, sobretudo na fase de preparação para a visita, que por fim não apresentou nenhuma atividade que gerasse valor. 
Figura 4 - Mapa de fluxo de valor (descentralizado)

\section{DESCENTRALIZADO (3x)}

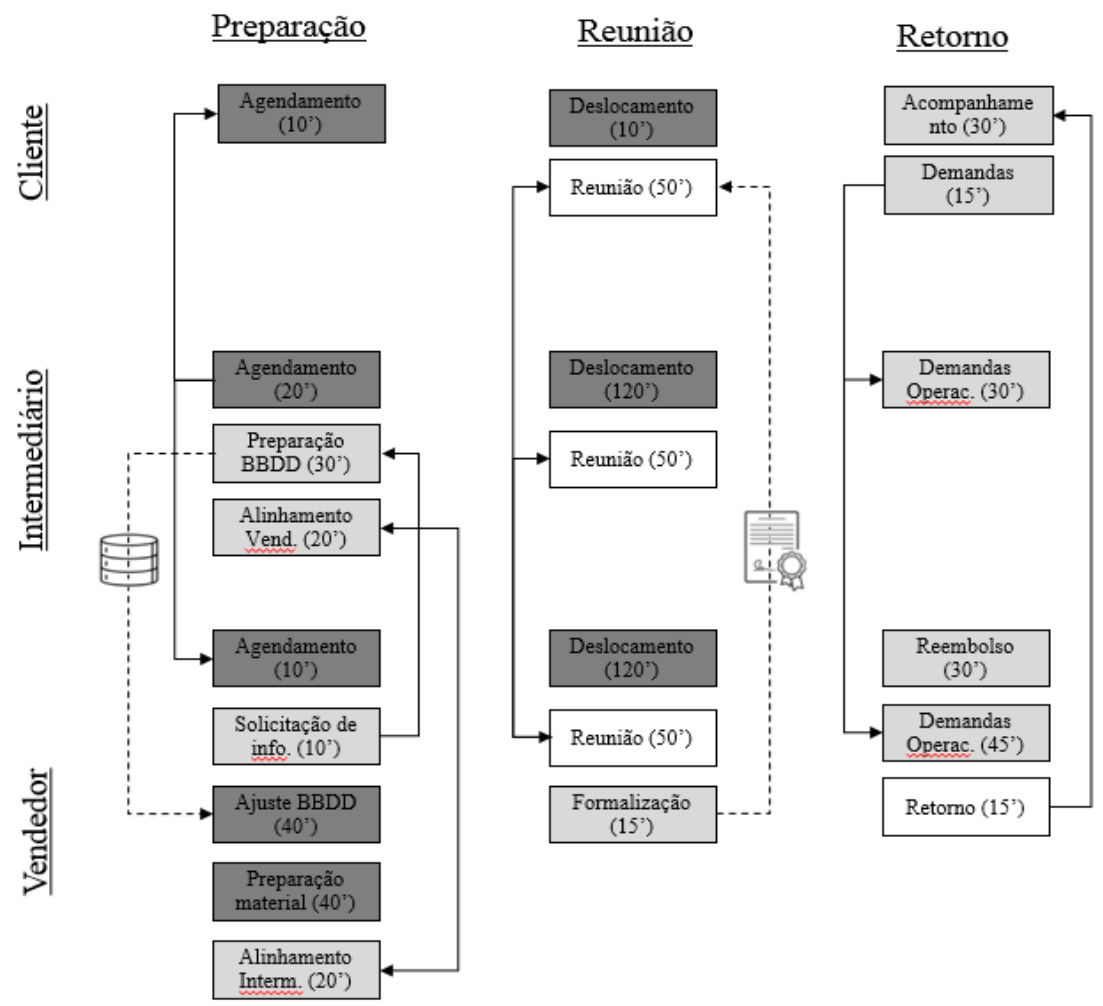

Fonte: Pesquisa de campo (2017)

Conforme a Tabela 1 cada etapa do processo como um todo correspondia a A $26 \%$, B $53 \%$ e C $21 \%$ do tempo total utilizado nesse processo. Isolando a figura do vendedor, pode-se verificar uma inversão do peso de cada etapa, A $30 \%$, B $47 \%$ e C $23 \%$ do tempo total do vendedor, onde o tempo gasto na preparação do da reunião $\mathbf{A}$, no qual não existe atividade que agregue valor é superior a etapa $\mathbf{B}$, na qual está presente a atividade que mais agrega valor, a "Reunião".

Tabela 1 - Distribuição do tempo por agentes do processo (descentralizado)

$\begin{array}{ccccc}\text { Agente } & \text { A } & \text { B } & \text { C } & \text { Total } \\ \text { Vendedor } & 1 \% & 8 \% & 6 \% & 15 \% \\ \text { Intermediário } & 9 \% & 22 \% & 4 \% & 35 \% \\ \text { Cliente } & 15 \% & 24 \% & 12 \% & 51 \% \\ \text { Total } & 26 \% & 53 \% & 21 \% & 100 \%\end{array}$

Fonte: Pesquisa de campo (2017)

As atividades que agregam valor ao cliente estão no momento da reunião em si B, como já mencionado anteriormente, e no retorno que o cliente recebe do vendedor em C um totalizando 55', conforme a Tabela 2 , isso corresponde a apenas $19 \%$ de todo tempo investido no processo (esse número é ainda menor isolando o vendedor na busca pelo contato com seu cliente 14\%), já as atividades necessárias que não agregam valor, correspondem a $47 \%$ de todo processo. Para o vendedor essas atividades necessárias que não agregam valor correspondem a 
$210^{\prime}$, ou seja, $53 \%$ de todo o seu tempo, sendo que $120^{\prime}$ se destina unicamente para o deslocamento.

Em todo mapa existem apenas dois momentos de troca de materiais entre os agentes, na fase A o intermediário envia a base de dados, com informações do cliente, para que o vendedor possa ajusta-la e então preparar o material que será apresentado no momento da reunião, e na fase $B$, na qual o vendedor apresentava no momento da reunião a formalização da renovação do contrato entre as partes, essas trocas de material foram identificadas como algo que gerasse valor ao cliente.

Tabela 2 - Distribuição dos tempo por tipo de atividade (descentralizado)

$\begin{array}{ccccc}\text { Tipo de atividade } & \text { A } & \text { B } & \text { C } & \text { Total } \\ \text { Agregam } & 0 \% & 19 \% & 2 \% & 21 \% \\ \text { Necessárias } & 15 \% & 32 \% & 0 \% & 47 \% \\ \text { Não agregam } & 10 \% & 2 \% & 19 \% & 31 \% \\ \text { Total } & 26 \% & 53 \% & 21 \% & 100 \%\end{array}$

Fonte: Pesquisa de campo (2017)

Com a somatória de tempos um vendedor seria capaz de atender no máximo 6 clientes por semana, contudo dada suas responsabilidades divididas entre intermediário e cliente, o número máximo de visitas a clientes se resumia em 2 clientes, apenas $33 \%$ de sua capacidade total, pois o resto de seu tempo estava focado no atendimento da figura do intermediário. Dessa forma o diagnóstico para a otimização desse processo está focado em:

a) Eliminação de atividades que não geram valor;

b) Converter atividades que não agregam valor a atividades que agreguem;

c) Diminuição dos tempos gastos em atividades necessárias;

d) Aumentar o tempo de atividades que agreguem valor;

e) Ampliar o número de visitas.

\section{MAPA PRESENTE - ATENDIMENTO CENTRALIZADO}

Apesar do mapeamento não ter ocorrido antes da mudança organizacional, muitos dos fatores elencados no diagnóstico do mapa do modelo descentralizado acabaram por refletir dentro da lógica do novo modelo de atendimento ao cliente. Nesse novo modelo o foco do vendedor passou a ser diretamente o cliente final e por isso não existe mais a necessidade do envolvimento do intermediário, conforme a Tabela 3. 
Tabela 3 - Distribuição dos tempos por agentes do processo (centralizado)

$\begin{array}{ccccc}\text { Agente } & \text { A } & \text { B } & \text { C } & \text { Total } \\ \text { Vendedor } & 5 \% & 17 \% & 11 \% & 32 \% \\ \text { Intermediário } & 0 \% & 0 \% & 0 \% & 0 \% \\ \text { Cliente } & 12 \% & 32 \% & 24 \% & 68 \% \\ \text { Total } & 17 \% & 49 \% & 35 \% & 100 \%\end{array}$

Fonte: Pesquisa de campo (2017)

Na figura 5 é possível identificar que no total foram eliminadas 9 atividades, sendo 6 do intermediário e mais 3 do vendedor. Considerando apenas a fase A, com a ausência do intermediário uma atividade que não agrega valor "Agendamento" passa integralmente ao vendedor dobrando o tempo necessário para ser finalizada. Mesmo com esse aumento registrou-se uma redução total de 70 ' nessa fase com a eliminação das atividades de "Ajuste de BBDD", necessária para se preparar o material para se levar no cliente, e as atividades de "Solicitação de Informações" e "Alinhamento Interno" que não agregavam valor.

Figura 5 - Mapa de fluxo de valor (centralizado)

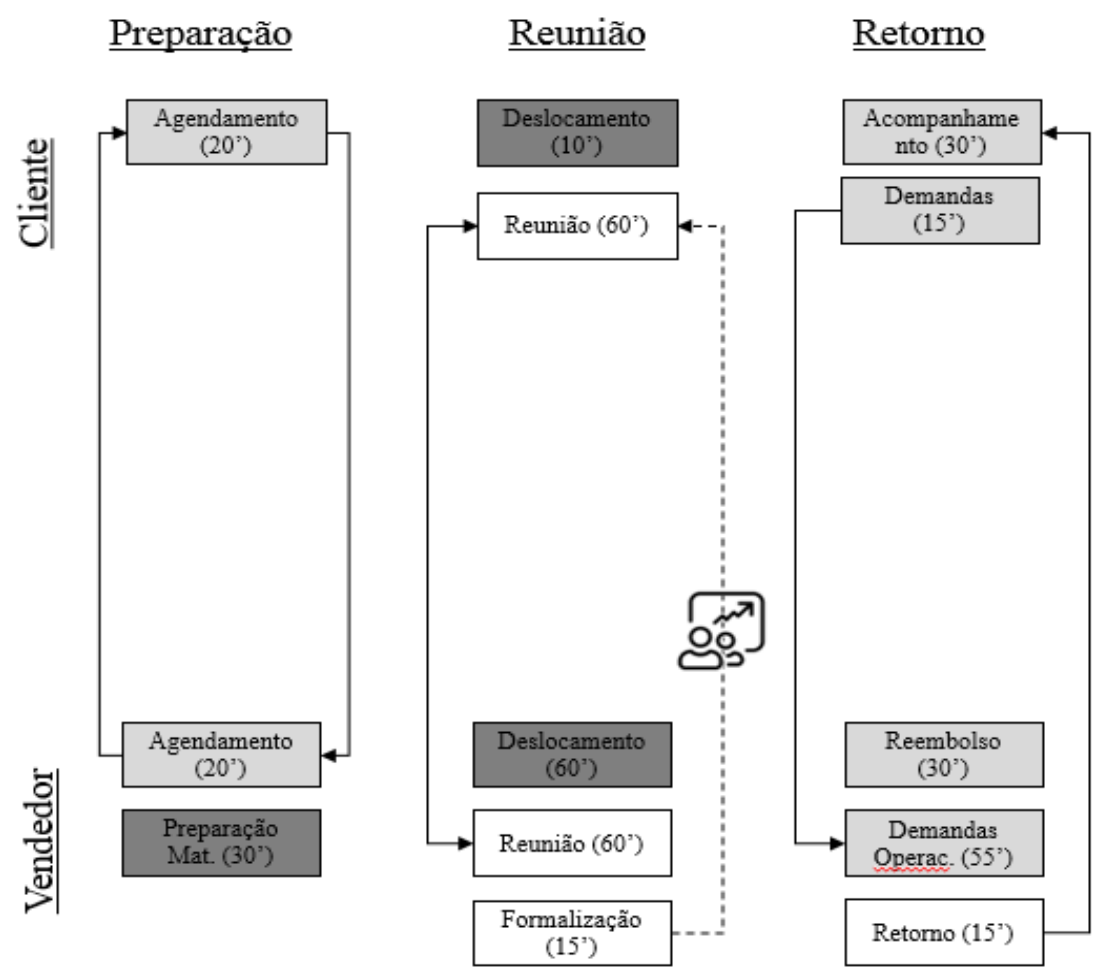

Fonte: Pesquisa de campo (2017)

Além disso, a atividade de "Preparação do material" reduziu em 10', essa redução em conjunto com a eliminação da atividade "Ajuste BBDD" é explicada pelo fato de áreas internas de suporte terem absorvido essa demanda, apresentando um material de maior qualidade com informações geradas internamente e de relevância para o cliente. Na etapa seguinte $\mathbf{B}$ o tempo da atividade que agregava valor, "Reunião" aumentou por não existir a figura do intermediário e de o vendedor apresentar um material mais completo ao cliente. 
O tempo de "Deslocamento" na etapa $\mathbf{B}$, também reduziu significativamente em $60^{\prime}$, visto que os vendedores se organizam para em um mesmo dia, visitar até 3 clientes. A atividade de "Formalização" também na etapa B, passa a ser identificada como agrega valor pelo fato de o cliente reconhecer no material apresentado na reunião - que é compartilhado somente após a reunião - como fonte de informação valiosa, segundo relato de um dos clientes "Eu quero que todos meus fornecedores me enviem painéis como este".

Por fim a etapa C, não apresentou qualquer alteração nas características das atividades, se não na eliminação da presença do intermediário. Apesar a reduções e readequações de atividade, a distribuição dos tempos o processo como um todo, ainda existem atividades as quais não agregam valor, "Reembolso" e "Demandas operacionais", consumindo um tempo que poderia agregar valor na relação entre cliente e vendedor.

De acordo com a Tabela 4, fica evidente que as atividades que agregam valor tiveram um ganho total de +15 pontos percentuais sobre o modelo anterior, contudo as atividades que não agregam também apresentaram um crescimento percentual de +9 pontos. Esse fato se deve principalmente a etapa $\mathbf{C}$, que durante a alteração organizacional não foi considerada, o que não refletiu na redução do tempo das atividades que não agregam valor ao cliente.

Tabela 4 - Distribuição dos tempo por tipo de atividade (centralizado)

$\begin{array}{ccccc}\text { Tipo de atividades } & \text { A } & \text { B } & \text { C } & \text { Total } \\ \text { Agregam } & 0 \% & 32 \% & 4 \% & 36 \% \\ \text { Necessárias } & 7 \% & 17 \% & 0 \% & 24 \% \\ \text { Não agregam } & 10 \% & 0 \% & 31 \% & 40 \% \\ \text { Total } & 17 \% & 49 \% & 35 \% & 100 \%\end{array}$

Fonte: Pesquisa de campo (2017)

Outro ponto importante a ser considerado é que dada a estrutura centralizada os vendedores passaram a atender um número muito maior de clientes, pelos tempos avaliados nessa nova estrutura eles teriam capacidade de atender no máximo 9 clientes por semana, contudo existe uma demanda de 12 atendimentos, uma ineficiência de $30 \%$.

\section{CONCLUSÃO}

Apesar da ferramenta de mapa de fluxo de valor ainda ser pouco explorada em serviços, a utilização dela para o mapeamento das atividades de um departamento de vendas poderia sim ter trazido benefícios mais consistentes na reestruturação organizacional. No estudo de caso fica evidente que é possível identificar os desperdícios a fim de atuar sobre deles, priorizando atividades que agreguem valor ao cliente.

Como a ferramenta não foi utilizada em um momento prévio a reestruturação organizacional, alguns pontos de otimização, sobretudo nas atividades que envolvem o retorno ao cliente não foram considerados, o que ainda hoje implica em desperdícios dentro da nova estrutura organizacional. 
Se tratando do relacionamento com o cliente fica evidente também que os benefícios encontrados com a aplicação da ferramenta estão relacionados a:

a) Criação de uma relação direta com o fornecedor, a partir da eliminação dos intermediários, que tornou todo o processo de comunicação mais eficiente, transformando atividades que não agregavam valor em atividades que agregam;

b) Troca de informações relevantes sobre a utilização dos serviços prestados. Na estrutura descentralizada o material enviado ao cliente se resumia na formalização da relação comercial entre as partes. Com restruturação todo um ferramental foi desenvolvido para munir o cliente com informações relevantes sobre a utilização dos serviços prestados;

c) Resolução rápida de demandas enviadas para seus fornecedores. Esse ponto identificado em ambos os mapas de valores não sofreu qualquer alteração durante a reestruturação organizacional, sendo ainda uma oportunidade de melhoria futura para a empresa objeto de estudo.

Os benefícios elencados estão relacionados com a percepção do cliente sobre a nova estrutura organizacional, nesse momento não foram considerados dados quantitativos sobre o desempenho da empresa antes ou depois da reestruturação que possam corroborara a utilização da ferramenta com um ganho competitivo e estratégico para a empresa prestadora de serviços. Isto posto o próximo passo para a validação da metodologia seria validar os ganhos reais para a empresa. Esse artigo ainda abre caminho para entender em quais outros departamentos de uma empresa prestadora de serviços o modelo poderia ser replicado na redução de desperdícios. 


\title{
Value stream mapping applied to organizational restructuring
}

\begin{abstract}
This article is the result of a case study carried out in a Brazilian company that provides transport services. This company achieved the market leadership in recent years but in the face of economic crises and the entry of new competitors fell to third place in its segment. In this context, several departments of the company underwent organizational restructuring targeting the cost reduction, but not always focused on process optimization. One of the most affected areas was the business-to-business (B2B) indirect sales department which was organized in a started a new centralized organization. New markets practices are directly related to the way organizations deal to their customers, yet developing and sustaining a customer loyalty relationship in B2B is still a difficult point to achieve, so that used the value stream map methodology to understand what wastes were in the old (decentralized) organizational structure that could have been optimized within the new (centralized) structure. In this way, this article aims to understand the viability of using the methodology and identify which sales processes generate value to the customer within B2B.The results showed that the use of the value flow mapping methodology applied to services, more specifically to the sales department, is effective in identifying the main waste. The use of the tool by the company, before the organizational change could have led to a structure even more prepared to serve the client, because in both maps were found the same opportunities for improvement.
\end{abstract}

KEYWORDS: Value stream map. Organizational structures. B2B. 


\section{REFERÊNCIAS}

BARBER, C. S., BRIAN C. TIETJE, B. C. A Research Agenda for Value Stream Mapping the Sales Process. Journal of Personal Selling \& Sales Management. v. 28 , n. 2, pp. 155-165, 2008. crossref

BONACCORSI, A., CARMIGNANI, G., ZAMMORI, F. Service Value Stream Management (SVSM): Developing Lean Thinking in the Service Industry. Journal of Service Science and Management. v. 4, pp. 428-439, 2011. crossref

BOSE, R. Customer relationship management: key components for IT success. Industrial Management \& Data Systems. v. 102, n. 2, pp. 89-97, 2002. crossref

BRAGLIA, M., CARMIGNANI, G., ZAMMORI, F. A New Value Stream Mapping Approach for Complex Production Systems. International Journal of Production Research. v. 44, n. 18/19, pp. 3929-3952, 2006. crossref

BRAGLIA, M., FROSOLINI, M., ZAMMORI, F. Uncertainty in Value Stream Mapping Analysis. International Journal of Logistic: Research and Application. v. 12, n. 6, pp. 435-453, 2009. crossref

CACERES, R. C., PAPAROIDAMIS, N. G. Service quality, relationship satisfaction, trust, commitment and business-to-business loyalty. European Journal of Marketing. v. 41 n. 7-8, pp. 836-867, 2007. crossref

EMILIANI, M. L., STEC, D. J. Using value-stream maps to improve leadership. Leadership \& Organization Development Journal. v. 25, n. 8, pp. 622-645, 2004. crossref

KEYTE, B., LOCHER, D. The Complete Lean Enterprise: Value Stream Mapping for Administrative and Office Processes, New York: Productivity Press, 2004. crossref

KOVOOR-MISRA, S. Understanding perceived organizational identity during crisis and change: A threat/opportunity framework. Journal of Organizational Change Management. v. 22 n. 5, 2009. crossref

LASA, I. S., LABURU, C. O., CASTRO VILA, R. An evaluation of the value streammapping tool. Business Process Management Journal. v. 14 n. 1, pp. 39-52, 2008. crossref 
MAY, T. Pesquisa social: questões, métodos e processos. Porto Alegre: Artmed, 2004.

$\mathrm{RICH}, \mathrm{M}$. K. The direction of marketing relationships. Journal of Business \& Industrial Marketing. v. 15, n. 2/3, pp. 170-9, 2000. crossref

ROTHER, M., SHOOK, J. Learning to See: Value Stream Mapping to Add Value and Eliminate Muda. Brookline, MA: Lean Enterprise Institute, 1999.

SHOU, W., WANG, J., WU, P., WANG, X., CHONG, H. A cross-sector review on the use of value stream mapping. International Journal of Production Research. 2017. crossref

SINGH, B., GARG, S. K., SHARMA, S. K. Value Stream Mapping: Literature Review and Implications for Indian Industry. The international Journal of Advanced Manufacturing Technology. v. 53, n. 5/8, pp. 799- 809, 2010.

STAKE, R. The case study method in social inquiry. In Norman K. Denzin \& Yvona Lincoln S. The American tradition in qualitative research. Vol. II. Thousand Oaks, California: Sage Publications. 2007.

TAPPING, D., SHUKER, T. Value Stream Management for the Lean Office: Eight Steps to Planning, Mapping, \& Sustaining Lean Improvements in Administrative Areas. New York: CRC Press, 2003. crossref

WOO, K. S., ENNEW, C. T. Business-to-business relationship quality: an IMP interaction-based conceptualization and measurement. European Journal of Marketing. v. 38, n. 9/10, pp. 1252-71, 2004. crossref

WU, S. T. P. The impact of customer knowledge and customer relationship management on service quality. International Journal of Quality and Service Sciences. v. 6, n. 1 pp. 77-96, 2014. crossref

XU, M., Walton, J. Gaining customer knowledge through analytical CRM. Industrial Management \& Data Systems. v. 105, n. 7, pp. 955-71, 2005. crossref

ZOLTNERS, A. A., SINHA, P., LORIMER, S. E. Sales Force Effectiveness: A Framework for Researchers and Practitioners. The Journal of Personal Selling and Sales Management. v. 28, n. 2, Enhancing Sales Force Productivity pp. 115131, 2008. 
Recebido: 17 set. 2017

Aprovado: 16 abr. 2018

DOI: 10.3895/gi.v14n2.7083

Como citar:

BONADIO,V. C.; MOURA, D. A. Mapeamento de fluxo de valor aplicado à reestruturação organizacional. R.

Gest. Industr., Ponta Grossa, v. 14, n. 2, p. 43-59, abr./jun. 2018. Disponível em:

<https://periodicos.utfpr.edu.br/rgi $>$. Acesso em: XXX.

Correspondência:

Vitor Carneiro Bonadio

Rua Jurandir Amaral, 61, Bragança Paulista, São Paulo, Brasil.

Direito autoral: Este artigo está licenciado sob os termos da Licença Creative Commons-Atribuição 4.0

Internacional.

\section{(c) (i)}

